\title{
Delayed contralateral traumatic carotid cavernous fistula after craniomaxillofacial fractures
}

\author{
Hyung-Sup Shim ${ }^{1}$, \\ Kyo Joon Kang', \\ Hyuk Joon $\mathrm{Choi}^{2}$, \\ Yeon Jin Jeong, \\ Jun Hee Byeon ${ }^{2}$ \\ ${ }^{1}$ Department of Plastic and \\ Reconstructive Surgery, St. Vincent's \\ Hospital, College of Medicine, The \\ Catholic University of Korea, Suwon; \\ ${ }^{2}$ Department of Plastic and \\ Reconstructive Surgery, Uijeongbu St. \\ Mary's Hospital, College of Medicine, \\ The Catholic University of Korea, \\ Uijeongbu; \\ ${ }^{3}$ Department of Plastic and \\ Reconstructive Surgery, Yeouido St. \\ Mary's Hospital, College of Medicine, \\ The Catholic University of Korea, Seoul, \\ Korea
}

\begin{abstract}
A carotid-cavernous sinus fistula is a rare condition in which an abnormal communication exists between the internal or external carotid artery and the cavernous sinus. It typically occurs within a few weeks after craniomaxillofacial trauma. In most cases, the carotid-cavernous sinus fistula occurs on the same side as the craniomaxillofacial fracture. We report a case of delayed carotidcavernous sinus fistula that developed symptoms 7 months after the craniomaxillofacial fracture. The fistula developed on the side opposite to that of the craniomaxillofacial fracture. Based on our experience with this case, we recommend a long follow-up period of 7-8 months after the occurrence of a craniomaxillofacial fracture. We also recommend that the follow-up should include consideration of the side contralateral to the injury.
\end{abstract}

Keywords: Carotid-cavernous sinus fistula / Facial bone fracture / Trauma

\section{INTRODUCTION}

A carotid-cavernous sinus fistula (CCF) is an abnormal communication between the internal or external carotid artery and the cavernous sinus. When arterial blood enters the cavernous sinus at high pressure, it interferes with normal venous return to the cavernous sinus. This causes engorgement of the draining vein and leads to a sudden engorgement and redness of the eye on the same side as the CCF [1].

CCF can occur either directly or indirectly, depending on the etiology. Direct CCF refers to a direct connection between the

\footnotetext{
Correspondence: Jun Hee Byeon

Department of Plastic and Reconstructive Surgery, Uijeongbu St. Mary's Hospital, College of Medicine, The Catholic University of Korea, 271 Cheonbo-ro, Uijeongbu 11765, Korea

E-mail: byeon@catholic.ac.kr

Received September 30, 2018 / Revised January 25, 2019 / Accepted January 28, 2019
}

cavernous sinus and the intracavernous segment of the internal carotid artery (ICA). Direct CCF accounts for $70 \%-90 \%$ of all $\mathrm{CCF}$ cases and occurs mostly after basal skull fractures. Indirect CCF refers to communication between the cavernous sinus and one or more branches of either or both the ICA or external carotid artery. Indirect CCF occurs mostly as a degenerative process in older patients with systemic hypertension and/or atherosclerosis [2,3].

Following any craniomaxillofacial trauma, direct CCF may be suspected if the patient has a bruit, progressive visual loss, pulsatile proptosis, progressive bulging of the eye, or eye pain. Diagnosis is possible via computed tomography $(\mathrm{CT})$, magnetic resonance imaging, or intra-arterial subtraction angiography. A symptoms of direct CCF typically develops within a few weeks after craniomaxillofacial trauma, and most occur on the same side as a craniomaxillofacial fracture. Reported cases of direct 
Table 1. Summary of reported cases of direct CCF following craniomaxillofacial trauma in the literature

\begin{tabular}{|c|c|c|c|c|}
\hline Study & Sex/age (yr) & Trauma site \& type & Symptom onset after trauma & CCF site \\
\hline Pulhorn et al. [4] & Male/45 & $\begin{array}{l}\text { Right orbital fracture } \\
\text { Right temporal bone fracture } \\
\text { Left frontoparietal skull fracture }\end{array}$ & $2 \mathrm{mo}$ & Left \\
\hline Yu et al. [3] & Male/49 & $\begin{array}{l}\text { Left zygomaticomaxillary complex fracture } \\
\text { Skull base fracture }\end{array}$ & Immediately & Left \\
\hline Schutz et al. [5] & Male/17 & $\begin{array}{l}\text { Right mandibular angle and parasymphysis fracture } \\
\text { Le Fort I fracture }\end{array}$ & 4 day & Right \\
\hline Chang and Cheng [6] & Female/27 & $\begin{array}{l}\text { Right zygomaticomaxillary complex fracture } \\
\text { Mandibular right subcondylar fracture }\end{array}$ & 3 wk & Right \\
\hline Nguyen et al. [7] & Male/34 & $\begin{array}{l}\text { Right orbital floor fracture } \\
\text { Skull base fracture } \\
\text { Right fronto zygomaticomaxillary complex fracture }\end{array}$ & $8 w k$ & Right \\
\hline Kim et al. [8] & Female/32 & Panfacial fractures with bilateral orbital fractures & Immediately & Left \\
\hline Paza et al. [9] & Female/18 & $\begin{array}{l}\text { Left mandibular parasymphysis and body fracture } \\
\text { Left orbital area contusion without fracture }\end{array}$ & Immediately & Left \\
\hline Wallick et al. [10] & Female/28 & $\begin{array}{l}\text { Right zygomatic arch fracture } \\
\text { Skull base fracture }\end{array}$ & $12 \mathrm{hr}$ & Right \\
\hline Keiser et al. [11] & Male/28 & $\begin{array}{l}\text { Left zygomatic arch step } \\
\text { Left orbital contusion }\end{array}$ & 2 wk & Left \\
\hline Zhu et al. [12] & Male/22 & $\begin{array}{l}\text { Skull base fracture } \\
\text { Subarachnoid hemorrhage } \\
\text { Epidural hematoma }\end{array}$ & $4 \mathrm{mo}$ & $\begin{array}{l}\text { Right (but symptoms } \\
\text { revealed in left eye) }\end{array}$ \\
\hline
\end{tabular}

CCF, carotid-cavernous sinus fistula.

CCF following craniomaxillofacial trauma are summarized in Table 1 [3-12]. We report a unique case of delayed CCF that developed symptoms 7 months after a craniomaxillofacial fracture and on the side opposite to that of the fracture.

\section{CASE REPORT}

A 19-year-old male patient was diagnosed with left frontal sinus and left medial blowout fracture after a motorcycle traffic collision (Fig. 1). Subsequently, he underwent surgery for open reduction of the left infraorbital rim and orbital floor fractures through a subciliary incision. Seven months later, he was readmitted for scar revision as he complained of limited ocular movement on lateral gaze, proptosis, and orbital bruit on the right side, which had first occurred 1 month prior to the visit. On examination, the pulsating exophthalmos and dependent exophthalmos on the right side disappeared from the worm's eye view. A follow-up facial bone CT was performed and revealed a space-occupying lesion in the right intraorbital area (Fig. 2). A right CCF was confirmed by performing CT angiography. It was treated with coil embolization (Fig. 3), and the fistula was occluded successfully. After the procedure, the proptosis and bruit gradually subsided. At the 4-month follow-up, the clinical appearance of the proptosis had improved, and the bruit had disappeared.
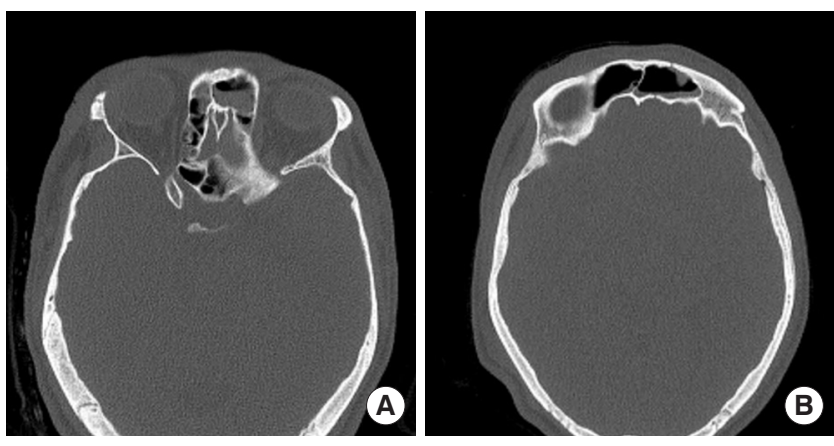

Fig. 1. (A, B) Initial facial bone computed tomography image showed left frontal sinus and left medial blowout fracture with otherwise normal intraorbital anatomy on both sides.
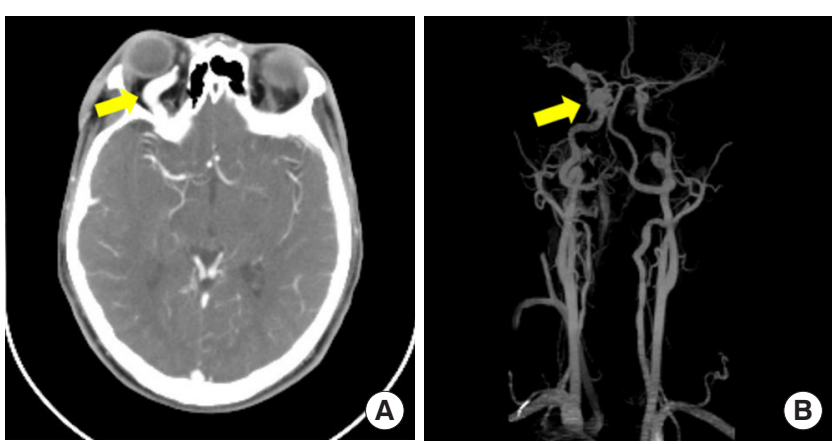

Fig. 2. (A, B) Head and neck computed tomography angiography images obtained 8 months after the primary procedure revealed a space-occupying lesion in the right intraorbital area and carotidcavernous sinus fistula (arrows). 

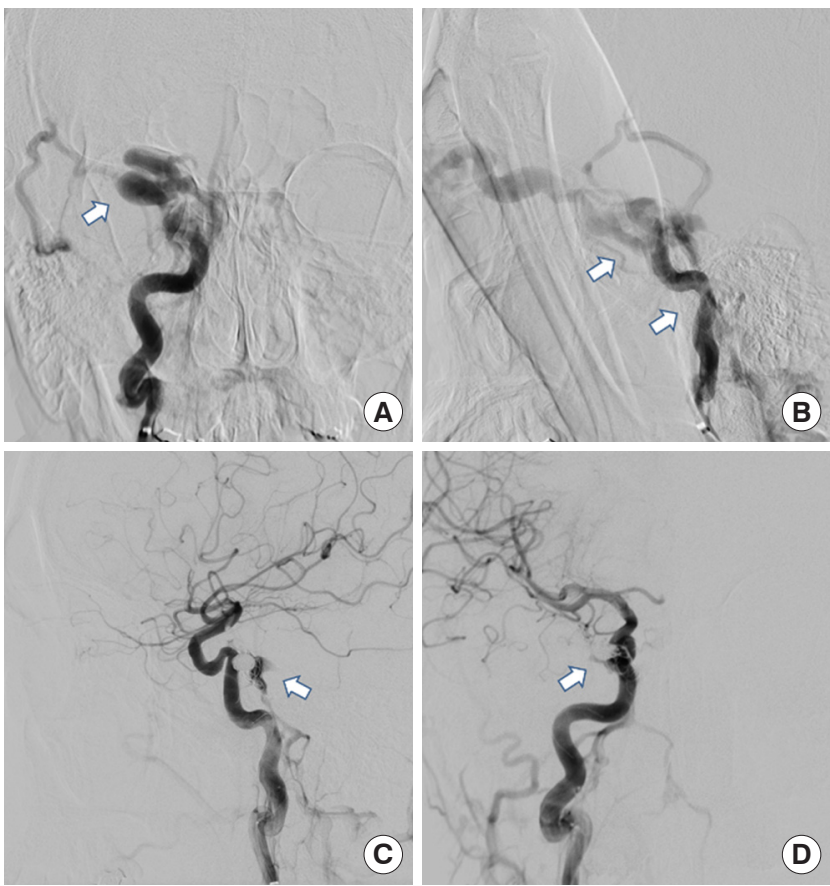

Fig. 3. (A, B) The preoperative angiogram images of the right internal carotid artery with traumatic direct carotid-cavernous sinus fistula (arrows). (C, D) The postoperative angiogram images of the right internal carotid artery with the successfully occluded fistula that was treated using the coil embolization procedure (arrows).

\section{DISCUSSION}

Craniofacial trauma is a major cause of CCF. When a patient has vascular complications, early detection and diagnosis of CCF are important for preserving visual acuity. Direct CCFs cause hemodynamic changes that are different from those caused by indirect CCFs. When a direct CCF is formed, arterial blood pressure and flow are directed into the cavernous sinus and can cause blood flow reversal and increased venous pressure. Such venous flow can affect the ophthalmic vein, leading to engorgement and orbital congestion, and manifestations such as exophthalmos, ophthalmic fremitus, chemosis, proptosis, and diplopia. Moreover, it can block the drainage of aqueous humor and increase intraocular pressure, which interferes with retinal perfusion and results in reduced visual acuity. In case of severe eye edema, the cranial nerves may become compressed and ischemia may develop in cranial nerves III, IV, V, and VI [3].

The optimal treatment for direct CCFs involves closure of the abnormal arteriovenous communication and preservation of ICA patency. The techniques used to achieve this include either surgical repair of the damaged portion of the intracavernous ICA, or intervention with electro thrombosis, embolization, or balloon occlusion of the fistula [10].
In 2018, Zhu et al. [12] reported a case of posttraumatic right carotid-cavernous fistula resulting in symptoms in the contralateral eye. Therefore, the final diagnosis must be confirmed by intra-arterial subtraction angiography examination. This ensures the correct treatment before the surgery is performed, which is important since a CCF can result in symptoms in the contralateral eye.

Ocular bruits, ocular pulsations, and thrills typically disappear immediately after CCF treatment, whereas eyelid engorgement, conjunctival chemosis, dilated conjunctival vessels, and elevated intraocular pressure may take several weeks to months to return to normal. In most cases of indirect CCF, symptoms disappear within 6 months after treatment, but in patients with direct CCF, proptosis, ophthalmoparesis, and visual loss may not disappear completely despite treatment $[3,8]$.

To our knowledge, the longest known duration from trauma until the symptoms of CCF onset has been 4 months. Moreover, there have been no reported cases of CCF occurring on the side contralateral to that of the initial craniomaxillofacial trauma. In our case, symptoms of CCF occurred 7 months after trauma on the side contralateral to that of the fracture. As timely treatment following CCF increases the possibility of restoring visual acuity, prompt diagnosis of CCF is essential. Therefore, the currently recommended follow-up period of 4 months is insufficient for monitoring the development of CCF following craniomaxillofacial trauma. Although rare, the case we have presented confirms that symptoms of traumatic CCF may occur as long as 7 months after the trauma.

We conclude that a follow-up period of 7-8 months is indicated after a craniomaxillofacial trauma. In addition, a more thorough CT review is needed as CCFs can occur on the side contralateral to that of the injury. With a longer follow-up period as recommended, the clinician can detect CCF early and easily, and initiate treatment at the proper time, thereby minimizing the risk of morbidity and improving the prognosis.

\section{NOTES}

\section{Conflict of interest}

No potential conflict of interest relevant to this article was reported.

\section{Ethical approval}

The study was approved by Catholic Medical Center Office of Human Research Protection Program (CMC OHRP) and performed in accordance with the principles of the Declaration of Helsinki. Written informed consent was obtained. 


\section{Patient consent}

The patient provided written informed consent for the publication and the use of his images.

\section{ORCID}

Hyung-Sup Shim https://orcid.org/0000-0001-5156-2239

Kyo Joon Kang https://orcid.org/0000-0002-0609-1324

Hyuk Joon Choi https://orcid.org/0000-0001-9681-628X

Yeon Jin Jeong https://orcid.org/0000-0003-0062-8546

Jun Hee Byeon https://orcid.org/0000-0002-7892-6239

\section{REFERENCES}

1. Nocini P, Lo Muzio L, Cortelazzi R, Barbaglio A. Cavernous sinus-carotid fistula: a complication of maxillofacial injury. Int J Oral Maxillofac Surg 1995;24:276-8.

2. Guimaraes AC, De Carvalho GM, Chone CT, Pfeilsticker LN. Carotid cavernous fistula: a rare complication of maxillofacial trauma. Head Neck Oncol 2014;6:23.

3. Yu SS, Lee SH, Shin HW, Cho PD. Traumatic carotid-cavernous sinus fistula in a patient with facial bone fractures. Arch Plast Surg 2015;42:791-3.

4. Pulhorn H, Chandran A, Nahser H, McMahon C. Case report: traumatic carotid-cavernous fistula. J Trauma Nurs 2016;23:424.

5. Schutz P, Bosnjakovic P, Abulhasan YB, AI-Sheikh T. Traumat- ic carotid-cavernous fistula in a multiple facial fractures patient: case report and literature review. Dent Traumatol 2014; 30:488-92.

6. Chang CM, Cheng CS. Late intracranial haemorrhage and subsequent carotid-cavernous sinus fistula after fracture of the facial bones. Br J Oral Maxillofac Surg 2013;51:e296-8.

7. Nguyen T, Cho YH, Jang YJ, Park MC, Shin SJ. Long delayed traumatic carotid-cavernous sinus fistula. J Craniofac Surg 2013; 24:e237-9.

8. Kim JW, Kim SJ, Kim MR. Traumatic carotid-cavernous sinus fistula accompanying abducens nerve (VI) palsy in blowout fractures: missed diagnosis of 'white-eyed shunt'. Int J Oral Maxillofac Surg 2013;42:470-3.

9. Paza AO, Farah GJ, Passeri LA. Traumatic carotid cavernous fistula associated with a mandibular fracture. Int J Oral Maxillofac Surg 2008;37:86-9.

10. Wallick K 4th, Davidson P, Shockley L. Traumatic carotid cavernous sinus fistula following a gunshot wound to the face. J Emerg Med 1997;15:23-9.

11. Keiser GJ, Zeidman A, Gold BD. Carotid cavernous fistula after minimal facial trauma: report of a case. Oral Surg Oral Med Oral Pathol 1991;71:549-51.

12. Zhu L, Liu B, Zhong J. Post-traumatic right carotid-cavernous fistula resulting in symptoms in the contralateral eye: a case report and literature review. BMC Ophthalmol 2018;18:183. 